\title{
Çocuk önkol kırıkları
}

\section{Pediatric forearm fractures}

\author{
Cemil Yıldız ${ }^{1}$ Yusuf Erdem² \\ 'SBÜ Gülhane Tıp Fakültesi, Ortopedi ve Travmatoloji Anabilim Dalı, Ankara \\ ${ }^{2}$ SB Gülhane Eğitim ve Araştırma Hastanesi, Ankara
}

\begin{abstract}
Çocukluk çağı kırıklarının önemli bir kısmını önkol kırıkları oluşturur. Çocuk kemiklerinin elastik oluşu ve kırık sonrası yeniden şekillenme potansiyeli, kırığın sıklıkla konservatif yöntemlerle tedavisini mümkün kılar. Önkol kırıklarında kırığın mekanizması, şekli ve lokalizasyonu tedaviyi yönlendirir. Distal kırıklarının çoğunluğunda konservatif yaklaşım yeterliyken, cisim kırıklarında cerrahi ihtiyacı artmaktadır. Cerrahi tedavide fleksibl intramedüller tespit yöntemi, diğer cerrahi seçeneklere göre, az invaziv oluşu ve rijid tespit sağlama gibi avantajları ile sık tercih edilen bir yöntemdir. Konservatif ve/veya cerrahi tedavi sonrası uygun fizik tedavi sürecinin sağlanması önemlidir. Çocukların kemiklerinin devam eden büyüme süreci nedeniyle, tedavi ve takibinin titizlikle yapılmasının, ilerleyen süreçte fonksiyonel bir kısıtlılık yaşanmaması açısından önemli olduğu unutulmamalıdır.
\end{abstract}

Anahtar sözcükler: çocuk; ortopedi; önkol; kırı; yeniden şekillenme; alçı; esnek intramedüller çivileme
Pediatric forearm fractures comprise the majority of childhood fractures. The elasticity of the child bones and the potential for remodeling after fracture make it possible to treat the fracture with conservative methods. The mechanism, shape and localization of the forearm fracture directs the treatment. Distal fractures are most commonly amenable to closed treatment methods. But in contrast, there is a low threshold for surgical stabilization in shaft fractures. Flexible intramedullary fixation method in surgical treatment is a preferred method compared to other surgical options with its advantages such as being less invasive and providing rigid fixation. It is important to ensure proper physical therapy after conservative and/or surgical treatment. Overall, with the reality of the ongoing growth process of childrens' bones, excellent outcomes can be expected if care is taken during the treatment and follow-up of these fractures appropriately to avoid a functional restriction in the future.

Key words: pediatrics; orthopaedics; forearm; fracture; remodelling; casting; flexible intramedullar nailing

beklentilerimizi çocuk ve ailesine aktarmamıza yardımcı olur. ${ }^{[1-3]}$ Çocuk önkol kırıkları en sık olarak önkolun distalinde, ikinci sıklıkta ise cisim bölgesinde (\%18-20) görülmektedir.

Tedavide, kırığın tipinin yanı sıra çocuğun yaşı ve kayma (deplasman) miktarı da önemlidir. Kırık sonrası uygun redüksiyonun sağlanması ve devamlılığında güçlükler oluşabilir, ancak yine de, erişkinlerin aksine, çocuk önkol kırıkları sonrası en etkin tedavi yöntemi kapalı redüksiyon ve uzun kol alçı uygulamasıdır. Konservatif tedavinin başarısında en önemli faktör, çocuklarda kaynamanın hızlı olması ve yeniden şekillenme (remodelling) potansiyelinin olmasıdır. Ancak, redüksiyonun sağlanamadığı veya kabul edilir sınırlarda olmadığı durumlarda cerrahi tedavi (intramedüller tespit veya plak osteosentez) uygulanır. ${ }^{[3]}$

- Illetişim adresi: Prof. Dr. Cemil Yıldız, SBÜ Gülhane Tıp Fakültesi, Ortopedi ve Travmatoloji Anabilim Dalı, Ankara Tel: 0312 - 3045501 e-posta: cyorto@yahoo.com

- Geliș tarihi: 2 Subat $2019 \quad$ Kabul tarihi: 2 Subat 2019 


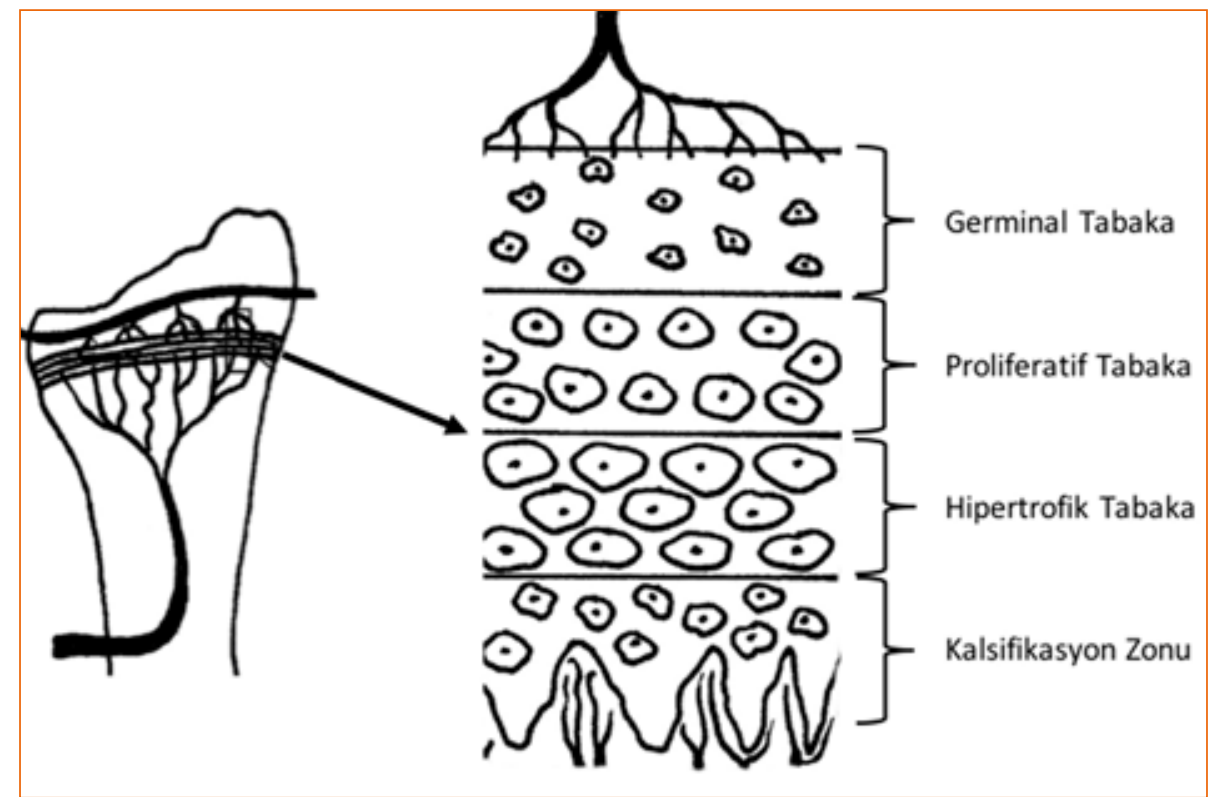

Şekil 1. Büyüme plağının katmanları ve mikro-anatomisi.

\section{ÇOCUK KEMIĞiNIN ÖZELLIKLERi}

Çocuk kemiklerinin uzaması enkondral ossifikasyon, genişlemesi apozisyonel ossifikasyon mekanizmaları ile olur. ${ }^{[3,4]}$ Erişkinin aksine, çocuk kemiklerini saran periost çok kalındır ve çoğunlukla kırık sonrası sağlam kalır. Bu durum, kırıkların redüksiyonunu kolaylaştırdığı gibi kaymasını da engelleyerek, konservatif tedavi olasılığını arttırır. Periostun hasarlandığı kırık tiplerinde redüksiyon zorlaşır ve cerrahi tedavi gerekebilir. Çocuk kemiğinin mineral içeriği erişkinden azdır ve daha az yoğundur. Young modülüsü (elastic modulus) düşük olduğu için enerjiyi absorbe eder ve kırılması için yüksek enerji gerektirir. ${ }^{[4]}$

\section{Büyüme Plağı Anatomisi}

Kondrosit matürasyonu, fizisin kemiğin longitudinal aksına dik dört tabakasında gerçekleşir (Şekil 1). Kondrositler olgunlaşırken ekstrasellüler matriksi

Tablo 1. Radius ve ulna epifizlerinin kemik uzunlamasına büyümesine katkısı

\begin{tabular}{lc}
\hline Proksimal radius epifizi & $\% 25$ \\
Distal radius epifizi & $\% 75$ \\
Proksimal ulna epifizi & $\% 80$ \\
Distal ulna epifizi & $\% 20$
\end{tabular}

azaltır. Bu durum en fazla hipertrofik tabakada gerçekleşir ki, en sık kırıklar da bu tabakadan olur. Son tabaka olan kalsifikasyon zonunda ise metafiziyel vaskülarizasyon, programlı kondrosit ölümüne, ekstrasellüler matriksin kalsifiye olmasına ve osteoblast/ostoklast oluşumu ile kemiğin remodelling özelliğine ulaşmasını sağlar.

\section{Yeniden Şekillenme (Remodelling) Potansiyeli}

Kırık sonrası açlanma geliştiğinde, yeniden şekillenme en fazla distal radius kırıklarında görülür. Çünkü kemik uzunlamasına büyümesinin \%75'i distal radius büyüme plağı ile olur (Tablo 1 ). Kırık sonrası rotasyonda ise yeniden şekillenme olmadığı kabul edilmektedir.

Yaşa bağlı olarak kırık çizgisinin yerine ve açılanma derecesine göre, ne kadar yeniden şekillenme olacağının bilinmesi tedavi planlamamız açısından önemlidir (Tablo 2).

Tablo 2. Çocuk önkol kırıklarında kabul edilebilir açılanma değerleri[ ${ }^{[4,5]}$

\begin{tabular}{lcc}
\hline Yaş & Kırık açısı & Malrotasyon \\
\hline $0-10$ yaş & $<15^{\circ}$ & $<45^{\circ}$ \\
10 yaş üzeri & $<10^{\circ}$ & $<30^{\circ}$ \\
İskelet gelişimini tamamlayan & $0^{\circ}$ & $0^{\circ}$ \\
veya $<2$ yıl kalan & &
\end{tabular}




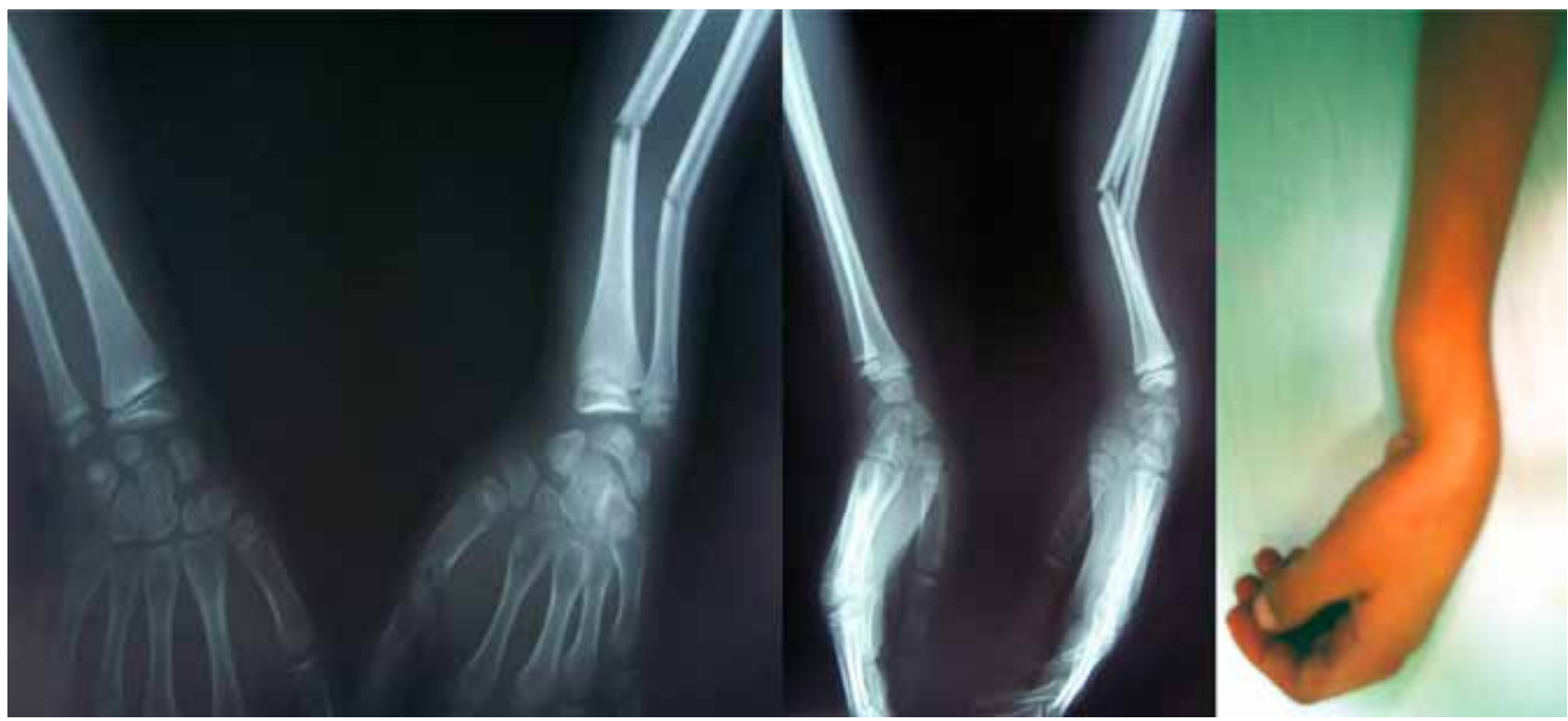

Şekil 2. Dokuz yaşında kız çocuğu; sol önkol yeşil ă̆aç kırı̆̆ı. Çocuk önkol kırıkları sıklıkla supinasyon tipidir ve apeks volar açılanma izlenir.

\section{ÇOCUK ÖNKOL KIRIKLARININ OLUŞ MEKANIZMALARI}

En sık görülen mekanizma açık el üzerine düşmedir. Nadiren, çocuk istismarı olaylarında önkola sopa ile vurulması gibi direkt mekanizmalarla da oluşabilmektedir. Ayrıca, bedenin başka yerlerinde morarmalar görülmesi veya iyileşme evresine girmiş diğer kırıkların da bulunması halinde, çocuk istismarı açısından dikkat edilmelidir. Çocuk düştüğünde ilk kırılan kemik genellikle radiustur, çünkü deforme edici güç önce radius üzerinden geçer ve sonrasında, travmanın şiddeti ile orantılı olarak, ulna kemiği de kırılabilir. Ayrıca, düşme sonrası genellikle kasların ve bağların etkisi ile rotasyonel bir hareket de oluşur. Rotasyon miktarı, kırı̆̆ın şeklini, seviyesini ve açılanmanın yönünü değiştirir. Radius ve ulnanın her ikisinin de aynı seviyeden kırıldığı durumlarda rotasyonel kuvvetlerin etkisi yok denecek kadar azdır. Her iki önkol kemiğinin de proksimal yarısı kaslar ile örtülü olduğu için daha güçlüdür. Distal yarısı ise tendinöz yapılarla sarılıdır ve travmaya daha açık olup, kırıkların çoğunluğu bu bölgede oluşur.

\section{ÇOCUK ÖNKOL KIRIKLARININ DEĞERLENDIRILMESI}

Önkolda ağrı, şişlik, krepitasyon ve belirgin şekil bozuklukları, ilk anda göze çarpan bulgulardır. Belirgin bir deformite varlığında, ebeveynin ilgili ekstremiteyi destekleyerek polikliniğe veya acile girişi tipiktir. Torus kırıklarında şişlik görülmez ve krepitasyon alınamaz. Plastik deformasyon ve yeşil ağaç kırıklarında ise ağrı rotasyon ile artar ve belirgin deformite görülebilir (Şekil 2). Ayrıca, çocuk istismarına bağlı oluşan kırıklar da göz ardı edilmemelidir. Çünkü, iki yaş altı çocuklarda görülen kırıkların dörtte biri istismara bağlıdır. Ekimoz, ısırık ve yanık, fiziksel istismarı düşündürebilecek klinik bulgulardır. Özellikle, eşzamanlı olarak görülen kosta kırıkları da oldukça önemli bir bulgudur. Bunun yanında, metafizer köşe ve epifiz plağı kırıkları da istismarı düşündürür. ${ }^{[6]}$ Kafa travması vb. kontrendikasyonun olmadığı olgularda anamnez ve fizik muayene öncesi ağrı kesici yapılmalıdır. Fizik muayenede, el bileği ve dirseğin de muayenesi önemlidir. Damar muayenesi yapılarak kompartman riski ekarte edilmelidir. Duyu muayenesinde; küçük parmağın ulnar tarafına dokunularak ulnar sinir, başparmak ve işaret parmağının palmar yüzüne dokunularak median sinir, birinci web aralığına dorsalden dokunulurak radyal sinir muayenesi yapılır. Motor muayenede; hastanın başparmağını kaldırması istenerek, posterior interosseöz sinir (radyal sinir motor dalı), ' $O$ işareti' yapması istenerek anterior interrosseöz sinir (median sinir motor dalı), başparmak abduksiyonu istenerek median sinir, parmak adduksiyonu ve küçük parmak fleksiyonu istenerek ulnar sinir muayeneleri yapılır. Tüm nörovasküler bulgular tedaviden önce kayıt altına alınmalıdır. Ancak ayrıntılı muayeneden sonra, redüksiyon ve alçı/atel tespitine geçilmelidir. 

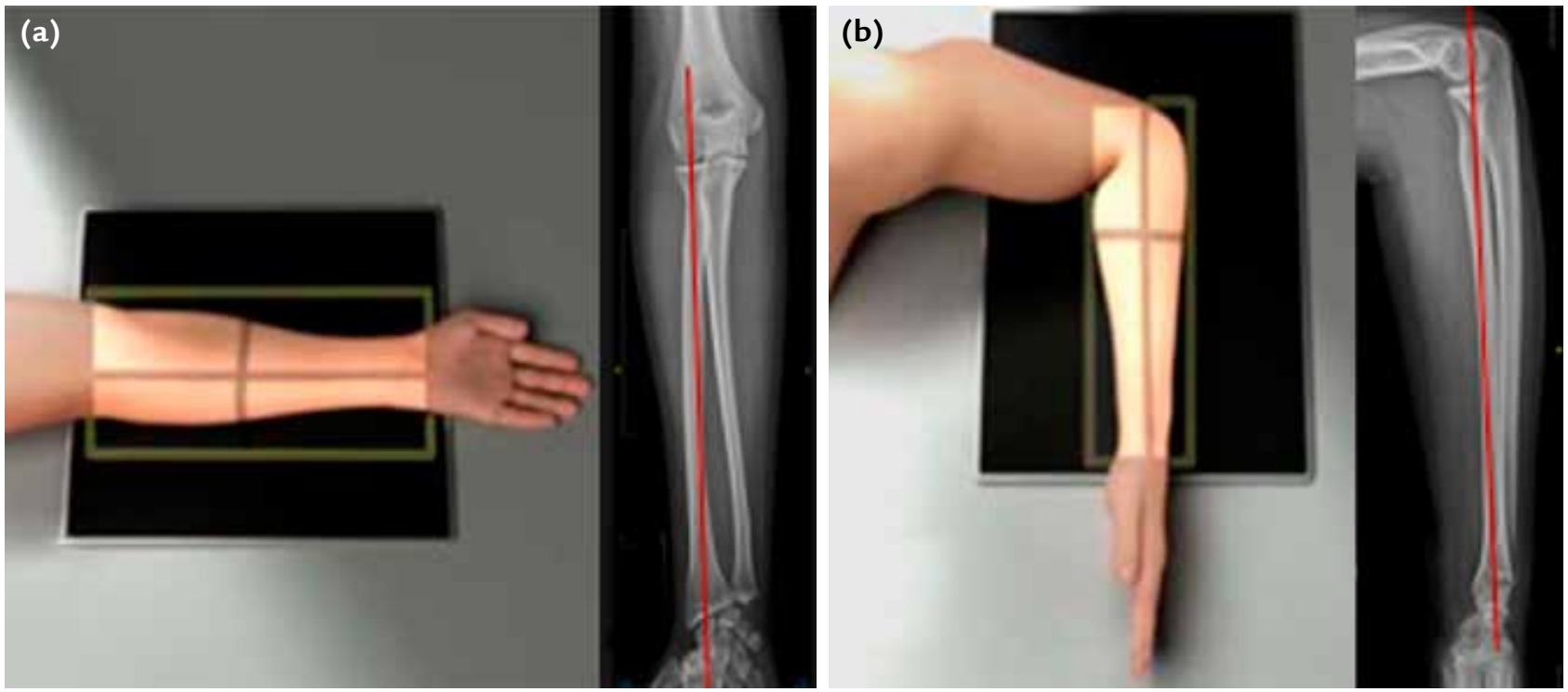

Şekil 3. a, b. İdeal ön-arka (a) ve yan (b) grafilerde radius uzun aksı boyunca çizilen çizgi kapitellumdan geçmelidir.

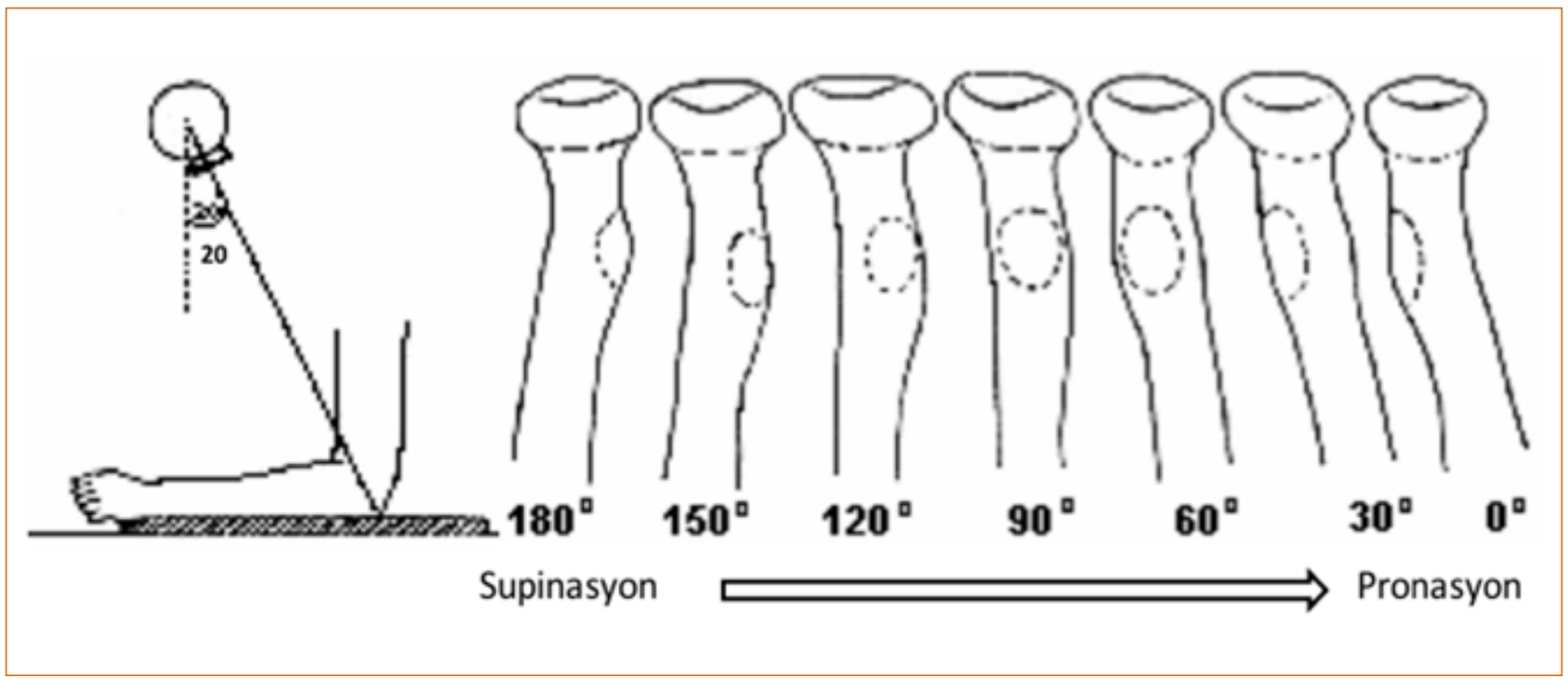

Şekil 4. Rotasyonun değerlendirilmesi için radyal tüberkülün görüntülendiği grafiler.

\section{Radyografik Değerlendirme}

Çocukta önkol kırık şüphesi olan bölgenin ön-arka ve yan grafileri ile birlikte dirsek ve el bileği eklemleri de radyolojik olarak değerlendirilmelidir. Standart grafilerde radius uzun aksı boyunca çizilen çizgi kapitellumdan geçmelidir. İdeal bir önkol ön-arka grafisinde radyal stiloid ve radyal tüberkül görülürken, yan grafide koronoid ve ulnar stiloid görülür (Şekil 3).

Kırık tipinin tam anlaşılamadığı durumlarda oblik grafilerin de çekilmesi uygun olacaktır. Bazı özel durumlarda çekilen ve radius proksimal parçanın rotasyonel deformitesini değerlendiren radius tüberkül grafisi de mevcuttur. Çünkü rotasyon, radiustaki eğimin ani kırılması ve çap değişikliği ile anlaşılır. Radyal tüberkülün konumu proksimal parçanın rotasyonunu tanımlar. Bu grafi, ulnanın subkutan kenarı kaset üzerinde iken ışın kaynağının $20^{\circ}$ olekranona doğru çevrilmesi ile elde edilir. Proksimal parça, radyal tüberkül mediyalde ise supinasyonda, lateralde ise pronasyonda, posteriorda ise nötral pozisyondadır (Şekil 4). 


\section{ÇOCUK ÖNKOL KIRIKLARININ \\ SINIFLANDIRILMASI}

Çocuk önkol kırıklarında proksimal ve distal radyoulnar eklemler sıklıkla sağlamdır. Kırık sınıflaması dört parametreye göre yapılır (Tablo 3):

- Anatomik lokalizasyon

- Kırık tipi

- Iilişkili yaralanma

- Açılanma yönü

\section{Anatomik Lokalizasyon}
i. Proksimal $1 / 3$
ii. Orta $1 / 3$ (diyafiz)
iii. Distal $1 / 3$ (fiziyel ve metafiziyel)

\section{Kırık Tipi}

a) Komplet olmayan
i. Yeşil ağaç kırığı
ii. Torus kırı̆gı
iii. Plastik deformasyon

b) Komplet kırık

\section{ilişkili Yaralanma}

i. Açık kırık

ii. Eklem hasarlı kırık

1) Proksimal radyoulnar hasarı ile seyreden Monteggia kırıklı çıkığı (çocuklarda sık)

2) Distal radyoulnar eklem hasarı ile seyreden Galeazzi kırıklı çıkığı (çocuklarda nadir)

iii. İnterosseöz membran hasarının da oluştuğu Essex-Lopresti kırığı (çocuklarda çok nadir)

\section{Açılanmanın yönü}
i. Supinasyon yaralanması
ii. Pronasyon yaralanması

\section{ÇOCUK ÖNKOL KIRIKLARININ TEDAVISi}

Çocuk önkol kırıklarında tedavinin amacı; uygun uzunluğun, dizilimin ve rotasyonun sağlanmasıdır. Normal önkol fonksiyonu, $100^{\circ}$ supinasyon-pronasyon arkının sağlanması ile oluşur. Çoğunlukla kapalı redüksiyon ve alçılama ile başarılı bir tedavi yapılabilir. Ancak, kabul edilebilir açılanma, rotasyon ve translasyon miktarları iyi bilinmelidir (Tablo 2). Bu sınırlar içinde ancak tam anatomik olmayan bir redüksiyon kabul edilebilir. Alçı

Tablo 3. Çocuk önkol kırıklarının farklı sınıflandırılmaları

\begin{tabular}{llll}
\hline Sınıflama Anatomik Lokalizasyon & Kırık Tipi & Açsıllanma Yönü
\end{tabular}
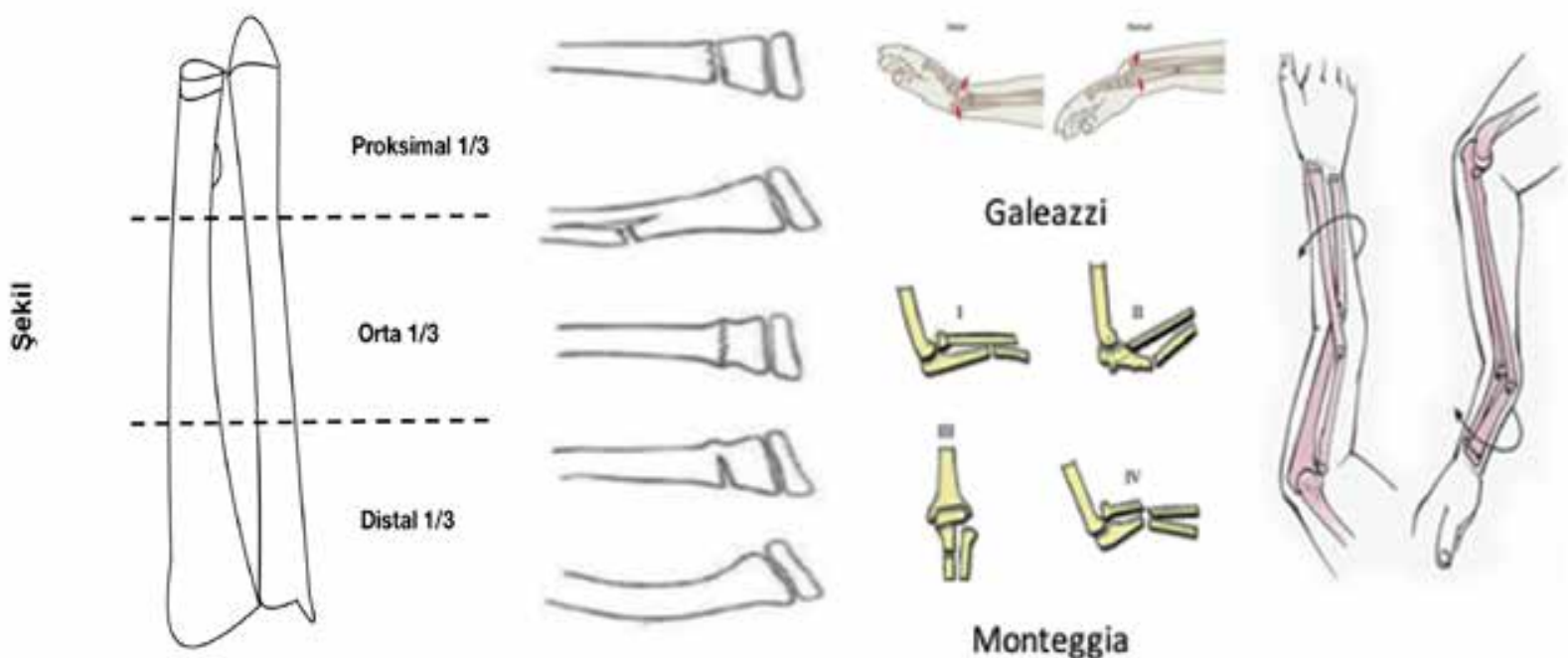

\section{Monteggia}




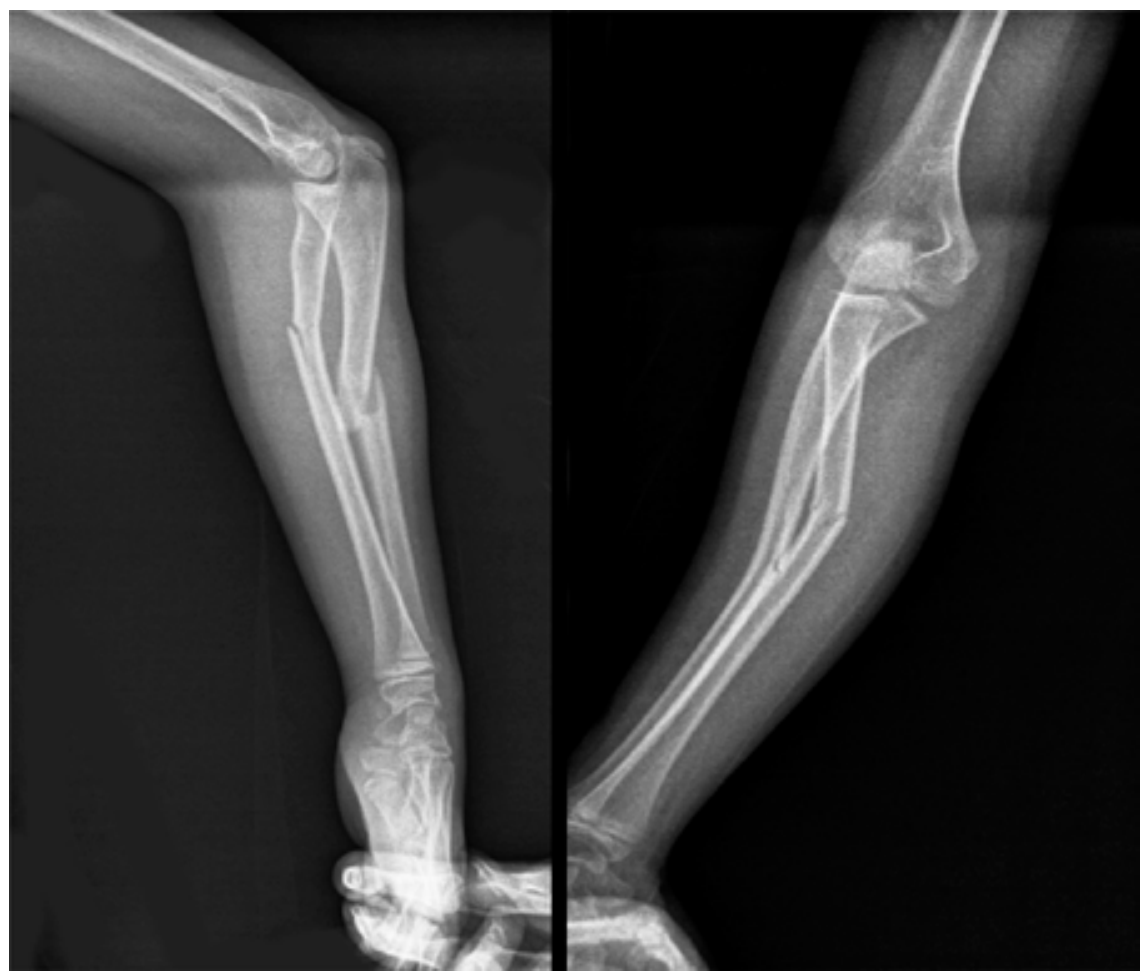

Şekil 5. On yaşında kız çocuğu; yeşil ağaç kırıklarında sık görülen sol önkol çift kemik kırı̆̆ı varyantı. Ulna tam kırık, radius plastik deformasyona uğramış.

sonrası oluşan rezidüel açılanma malrotasyona bağıdır ve manipülasyon esnasında kırığa neden olan kurvetin karşı yönünde rotasyon uygulanması gereklidir. ${ }^{[4,7-8]}$

\section{Redüksiyon ve Alçılama}

Yeşil ağaç ve Torus kırıklarının çoğunluğu supinasyon tipidir ve apeksi volarde olan bir açılanma izlenir. Pronasyon kuvveti ile redüksiyon sağlanır. Tam tersi durumlarda (apeks dorsal kırık), kırık mekanizması pronasyon kuvvetine bağlı oluşur ve supinasyonda redüksiyon ile dizilim sağlanır. Önkol yeşil ağaç kırıkları çoğunlukla çift kemik kırıkları olarak karşımıza çıkar. Ancak, sık görülen bir varyasyonu ise bir kemiğin plastik deformasyonu, diğer kemiğin ise tam kırığı şeklindedir (Şekil 5).

Tam (komplet) kırıklar, sıklıkla önkol orta 1/3'lük kısımda izlenir. Dolayısıyla, redüksiyon sonrası kolun nötralde veya bir miktar supinasyonda alçı tespitinin yapılması, rotasyon ve açılanmayı önlemesi açısından uygun olacaktır. Eğer bu tip kırıkların pronasyonda tespiti yapılır ise, supinasyonun fonksiyel kaybı ve yumuşak doku kontraktürleri gibi komplikasyonlarla karşılaşırız. ${ }^{[9]}$

Distal radius metafız kırıklarının redüksiyonu göründüğü kadar kolay değildir, ancak rotasyonel ve açılanma kabul edilebilir sınırlarda ise, kırık uçlarının çok az da olsa uç uca gelmeyip, birbirinin üzerine binmesi kabul edilebilir durumdur. ${ }^{[10]}$ Bu kırıklarda yüksek oranda alçı sonrası redüksiyon kaybı izlenir ve ilk yedi gün sıkı takip edilmesi gerekir. Ayrıca, bu tip kırıklarda, ulnanın sağlam olduğu durumlarda, alçı içerisinde el bileğinin pozisyonu çok önemli değildir. Ancak, brakiyoradyalisin deforme edici etkisinden kurtulmak için supinasyonda olması önerilir. ${ }^{[11]} \mathrm{Alçı,} \mathrm{uzun} \mathrm{kol} \mathrm{ola-}$ cak şekilde ve dirsek $90^{\circ}$ fleksiyonda iken uygulanır. Önkolda anterior ve posteriordan bastırılarak, interosseöz aralığın kapanması engellenirken, ulnanın da daha rijid tespitinin devamı sağlanır. Kolda, mediyal ve lateral alçı şekillendirmesi ile alçının dirsekten kayması engellenirken, ödem sonrası kırık hattında redüksiyon kaybının da önüne geçilmiş olur. Redüksiyon kaybı gelişmez ise alçı tespiti 6-8 hafta devam eder.

Alçılama, redüksiyonun sağlandığı yönde ve şekilde uygulanmalı ve alçı içerisinde kırığın rotasyonuna izin vermemelidir. Bunun yanında, önkol kırıklarında kırık hattını sabitlemede genel bir görüş mevcuttur. Redüksiyon sonrası önkolu; kırık hattı proksimalde ise supinasyonda, ortada ise nötral pozisyonda, distalde ise pronasyonda sabitlemek önerilmektedir. ${ }^{[4-11]}$ 

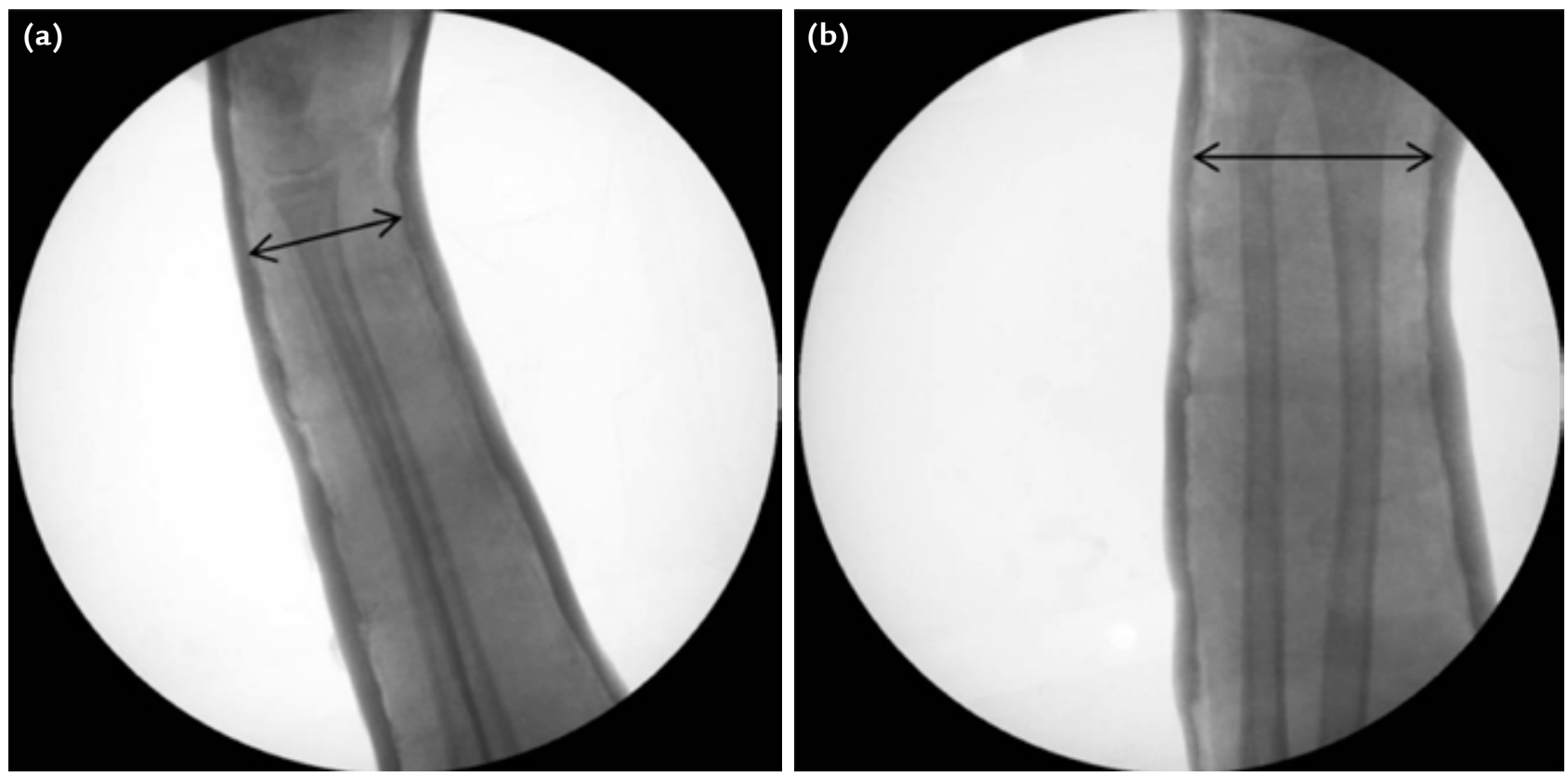

Şekil 6. a, b. Sagittal planda kırık hattında ölçülen çapın (a) koronal planda kırık hattında ölçülen çapa (b) bölünmesi ile alçı indeks çapı bulunur ve 0,7-0,8'den küçük olmalıdır.

Alçının şekillendirilmesi de önem arz eder. Özellikle alçı indeks çapının 0,7-0,8'den küçük olması önerilir. ${ }^{[7]} A / c ̧ ı$ indeks çapı sagittal alçı indeksinin/koronal alçı indeksine bölünmesi ile bulunur (Şekil 6).

Önkol kırıklarında, alçıya şekil verilmesi esnasında volar ve dorsalden bastırılarak redüksiyonun korunması, interosseöz aralığın daralmasını koruyarak kırık stabilizasyonunu arttırır (Şekil 7). Ayrıca, dirsek üstünde mediyal ve lateralden basılarak şekil verilmesi, alçının kaymasını önleyerek redüksiyon kaybını engelleyen bir manevradır (Şekil 8).

\section{Cerrahi Endikasyonlar}

Çocuk önkol kırıklarının tedavisinde ameliyat çoğunlukla gerekmez. Ancak, son yıllarda cerrahi oranlarında artış görülmektedir (Tablo 4). Cerrahi endikasyonları;

- redüksiyon sonrası kabul edilebilir sınırlar dışında olan,

- redükte edilemeyen,

- redüksiyon kaybı olan (konservatif tedavinin başarısız olduğu),

- açık,

- patolojik,

- aynı taraf humerus ve

- damar-sinir yaralanmasının eşlik ettiği kırıklar şeklinde sıralamak mümkündür (Tablo 5). ${ }^{17]}$
Günlük pratiğimizde, özellikle 10 yaş ve üzeri çocuklarda cerrahiye yönelim fazla görünse de prevalansı \%5-10'dur. Bunun en önemli nedeni plastik deformasyondur. Plastik deformasyon, çocukluk çağında travma sonrası kemiklerde elastisite nedeniyle eğilmenin olmasıdır. Teorik olarak tüm kemiklerde görülebilse de pratikte en sık çocuk önkol kırıklarında izlenir. Plastik deformasyona uğrayan kemik, açılanma $20^{\circ}$ 'nin altında ise sıklıkla kendiliğinden düzelme eğilimindedir.

\section{Çocuk Önkol Kırıklarında Cerrahi Yöntemler ve Teknikler}

Cerrahi yöntemleri başlıca dört kategoride incelemek mümkündür:

1) Kapalı redüksiyon ve Kirschner teli (K-teli) tespiti.

2) Kapalı redüksiyon ve fleksibl intramedüller tel tespiti.

3) Açı redüksiyon ve K-teli veya fleksibl intramedüller tel tespiti.

4) Açık redüksiyon ve plak osteosentezi.

\section{Kapalı redüksiyon ve K-teli tespiti}

Genellikle redüksiyon sağlanamayan veya stabil olmayan radius distal uç kırıkları sonrası ameliyathane şartlarında ve skopi eşliğinde uygulanır. 


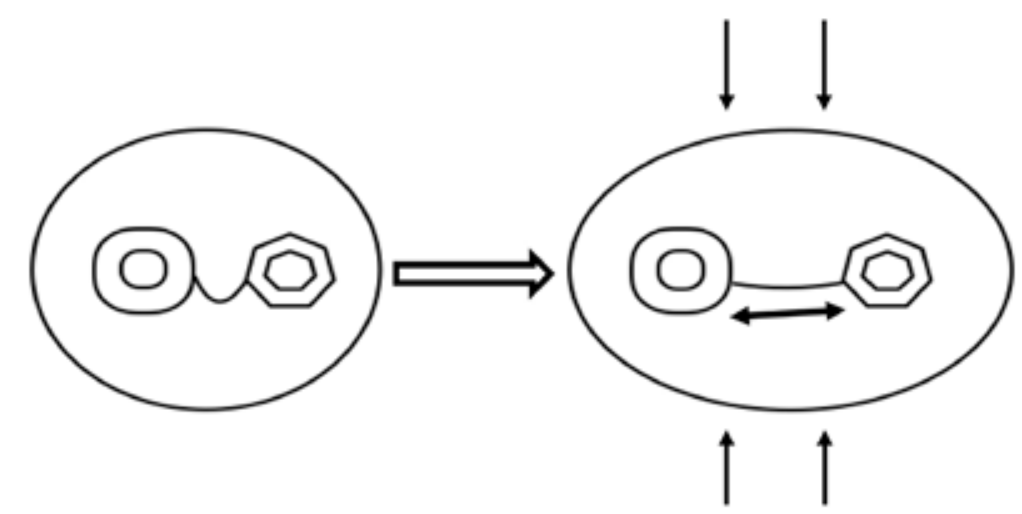

Şekil 7. Üstten ve alttan bastırarak molding sonrası interosseöz aralığın açılması ile alçı içerisinde kırık parçalarının stabil tespiti sağlanır.

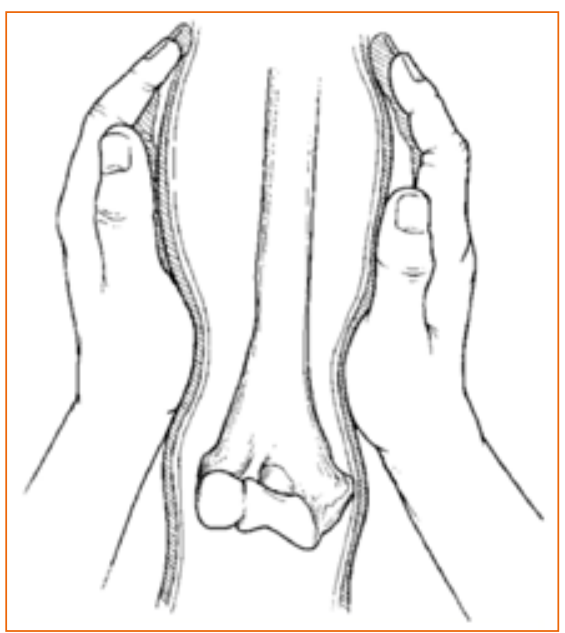

Şekil 8. Dirsek üstü yanlardan bastırarak alçıya şekil verilmesi ile alçının kaymasının ve ödem geriledikten sonra kırık hattında açılanmanın önlenmesi.

Tablo 4. Çocuk önkol kırıkları cerrahi tedavisi ile ilgili son beş yıldaki yayınlara baktığımızda intramedüller tespitin çok yaygın olarak tercih edildiği görülmektedir.

\begin{tabular}{|c|c|c|c|c|c|c|}
\hline & YII & Hasta sayısı & Kırık tipi & Yaş & Teknik & Komplikasyonlar \\
\hline Antabak ve ark. ${ }^{[9]}$ & 2013 & 88 & Önkol cisim & $10,5 \pm 2,59$ & İntramedüller tespit & $\begin{array}{l}1 \text { gecikmiş kaynama } \\
6 \text { radyal sinir hipoestezisi } \\
1 \text { tekrar kırık }\end{array}$ \\
\hline Ho ve ark. ${ }^{[14]}$ & 2013 & 117 & Önkol cisim & $8,56 \pm 2$ & İntramedüller tespit & Belirtilmemiş \\
\hline Du ve ark. ${ }^{[15]}$ & 2016 & 49 & Önkol cisim & $8,56 \pm 2,1$ & İntramedüller tespit & $\begin{array}{l}1 \text { tekrar kırık } \\
5 \text { enfeksiyon }\end{array}$ \\
\hline Gennaro ve ark. ${ }^{[16]}$ & 2017 & 15 & $\begin{array}{l}\text { Önkol cisim } \\
\text { Önkol distal }\end{array}$ & 8,5 & $\begin{array}{l}\text { K-teli tespiti } \\
\text { Plak osteosentez } \\
\text { İntramedüller tespit }\end{array}$ & $\begin{array}{l}1 \text { olekranon bursiti } \\
1 \text { radyal sinir lezyonu } \\
1 \text { K-teli malpozisyonu } \\
1 \text { tekrar kırık }\end{array}$ \\
\hline Sahin ve ark. ${ }^{[17]}$ & 2017 & 40 & Önkol cisim & $11,60 \pm 2,6$ & $\begin{array}{l}\text { İntramedüller tespit } \\
\text { K-teli tespiti }\end{array}$ & $\begin{array}{l}2 \text { gecikmiş kaynama } \\
1 \text { pin dibi enfeksiyonu } \\
1 \text { tekrar kırı }\end{array}$ \\
\hline Han B ve ark. ${ }^{[18]}$ & 2018 & 267 & $\begin{array}{l}122 \text { Önkol cisim } \\
100 \text { Önkol distal } \\
45 \text { Önkol proksimal }\end{array}$ & $6,8 \pm 2,59$ & İntramedüller tespit & 11 tekrar kırık \\
\hline
\end{tabular}

Tablo 5. Çocuk önkol kırıklarında cerrahi endikasyonlar

Çocuk önkol kırıklarında cerrahi endikasyonlar

1. Redüksiyon sonrası uygun olmayan açı

2. Redükte edilemeyen kırıklar

3. Redüksiyon kaybı olan kırıklar

4. Açık kırıklar

5. Patolojik kırıklar

6. Aynı taraf humerus kırıkları (yüzen dirsek)

7. Damar-sinir yaralanmasının eşlik ettiği kırıklar
2. Kapalı redüksiyon ve esnek (fleksibl) intramedüller çivi tespiti

Son 25 yılda sık kullanılmaya başlayan bu teknik, redüksiyonun sağlanamadığı önkol cisim kırıklarında, stabil olmayan kırık paterni varlığında, redükte edilemeyen kırıklarda, açık kırık ve tekrarlayan önkol kırıklarında ameliyathane şartlarında ve skopi eşliğinde uygulanır (Şekil 9).

İntramedüller fleksibl çivi tespitinin minimal invaziv oluşu, ameliyat süresinin kısa oluşu, periosta zarar 


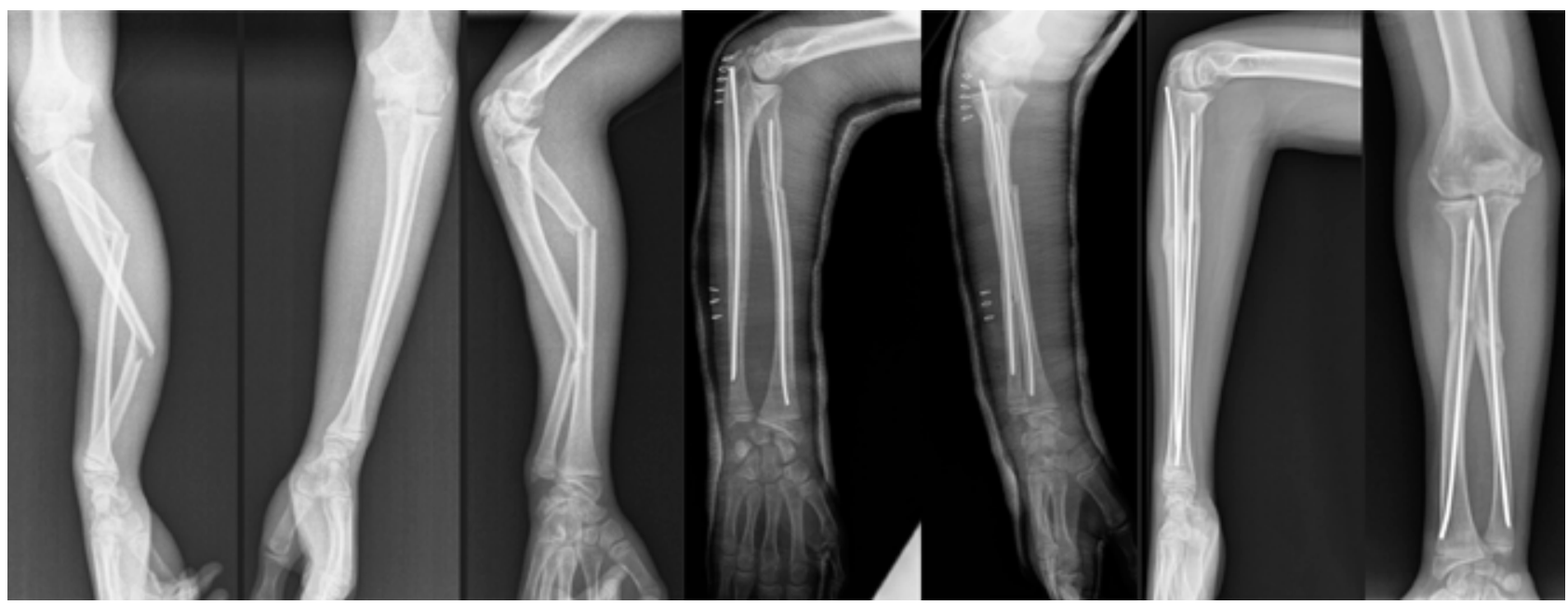

Şekil 9. İntramedüller elastik çivi tekniği ile tedavi edilmiş önkol kırı̆̆ı. Kırık uçlarındaki bir miktar translasyonun, mikro-harekete bağlı kaynamayı hızlandırdığı bilinmektedir. Kaynama sonrası uygun dizilim izlenmekte.

verilmemesi, plak osteosentezine göre ucuz oluşu ve tüm bunlara bağlı hastanede yatış süresinin kısa oluşu avantajlarıdır. ${ }^{[17]}$

Çocuk önkol kırığının intramedüller tespitinde cerrahi teknik: İntramedüller fleksibl çivi uygulamasına kemik deformitesi fazla olan kemikten başlanması önerilir. Radius distal uç fizis proksimalinde lister tüberkülü üzerinden longitudinal cilt insizyonu sonrası, radyal sinirin duyu dalı ve ekstensör tendonlar korunarak radiusa ulaşılır, radius distal epifizinin $2 \mathrm{~cm}$ proksimalinden giriş deliği açılır. Çivi retrograd olarak floroskopi eşliğinde proksimal parçaya gönderilerek redüksiyon sağlanır.

Ulnanın tespiti için olekranon lateral kenarından longitudinal cilt insizyonu yapılarak, intramedüller elastik çivi antegrad olarak ulna proksimalinden distal parçaya doğru gönderilir. Kırık hattı ulna orta noktasının distalinde ise, ulna tespitinin distalden yapılması uygun olacaktır. Distal ulna girişi ile tespit, ulnanın distal stiloidinin subkutan doku altında rahat hissedilmesi sayesinde rahatlıkla uygulanabilir.

Çivilerin fizisi geçmemesine ve çivi çapının, diyafiz iç çapının en az \%50'sini doldurmuş olmasına dikkat edilmesi, sağlam tespit ve tespit sonrası başarısızlığa neden olabilecek komplikasyonları önlemesi açısından önemlidir.

Bu tekniğin dezavantajları olarak, uygulama sonrası telin kemiğin içine migre olması ve plak osteosenteze göre daha geç harekete başlanması belirtilmektedir. ${ }^{[18]}$
İntramedüller tespit, tek kemiğe uygulanabildiği gibi iki kemiğe de uygulanabilir. Son yıllarda tek kemiğin intramedüller tespitinin de iki kemik tespiti sonrası sonuçlar kadar başarılı olduğu gösterilmiştir. ${ }^{[18]}$ Literatürde, hasta yaşı küçük olanlarda ve distal önkol çift kemik kırıklarında, tek kemiğe uygulamanın yüksek yeniden şekilllenme kapasitesi gösterdiği belirtilmektedir. ${ }^{[14]}$ Bu durum, özellikle metadiyafiziyel bileşkede oluşan kırıklarda çapraz veya distalden radiusun K-teli tespiti ile düzeltilmesi esasına dayanır. Özellikle erkeklerde 10, kızlarda sekiz yaş altında tek kemik tespiti önerilmektedir. ${ }^{[7,18]}$ Kullanılan intramedüller implantlar minimum 8-12 hafta sonra çıkarılır.

İntramedüller tel tespiti sonrası kırıkların \%85'inde herhangi bir komplikasyon izlenmezken, kalan kısmında izlenen komplikasyonlar da yara yeri ile ilişkili problemlerdir. Az da olsa, telin giriş yerine bağlı yüzeyel radyal sinir hasarı bildirilmektedir (Şekil 10). Uzun dönem izlemde, fonksiyonel bir kayıp olmadan tam iyileşme sağlanır.

\section{Açık redüksiyon ve K-teli veya fleksibl intramedüller çivi tespiti}

Periostun veya kırık paterninin kapalı redüksiyona izin vermediği durumlarda uygulanır. Açık redüksiyon ve K-teli ile tespit uygulaması, distal kırıklar hariç önerilmez. Bu olgularda, kırık hattının açılarak redüksiyonun sağlanması sonrası fleksibl intramedüller tespit uygun tercihtir. Kırık hattının açılması ve redüksiyon esnasında periosta zarar verilmemesi, dikkat edilmesi gereken bir durumdur. 


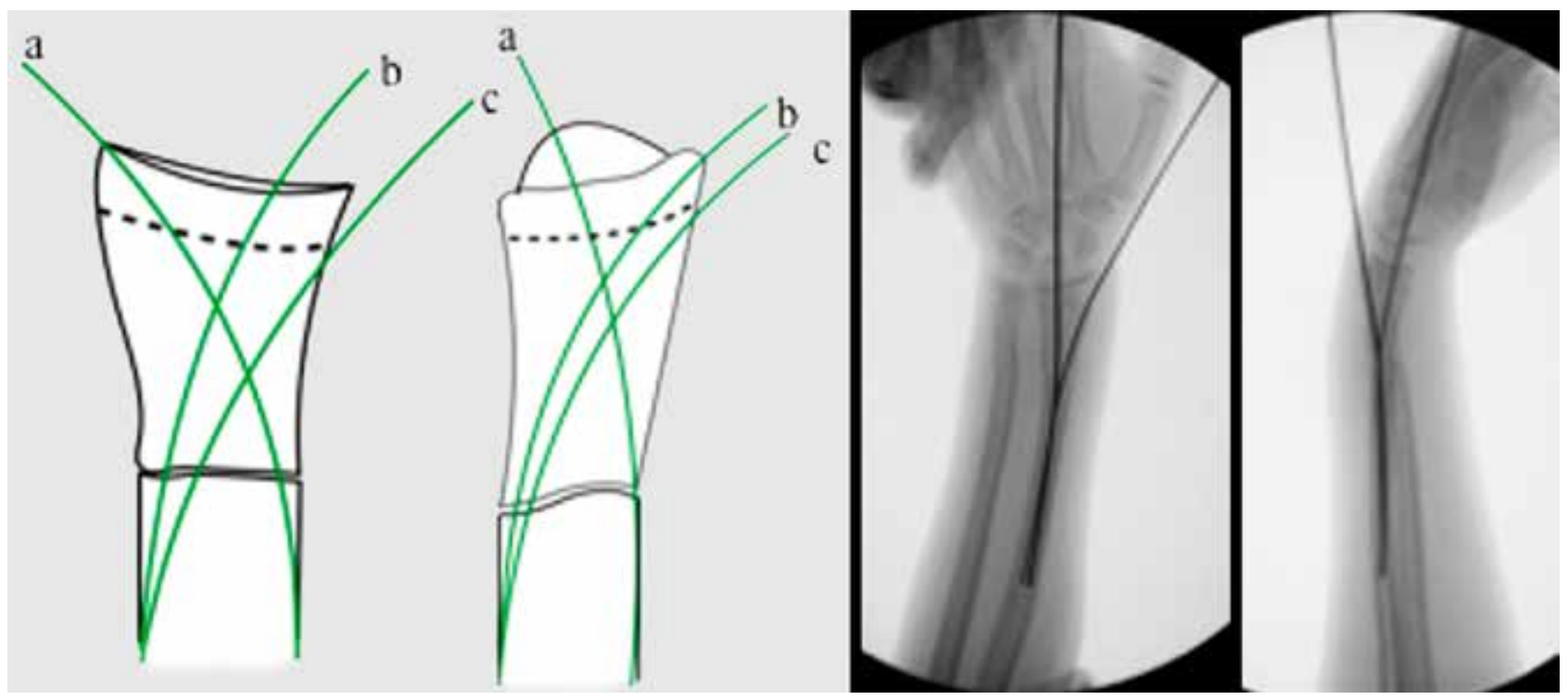

Şekil 10. Distal $1 / 3$ önkol çift kemik kırıklarında (metadiyafiziyel), tek kemik tespiti çoğunlukla yeterlidir. K-telleri radyal stiloid ve tüberkülden transfiziyel [a ve b] veya transkortikal [c] yerleştirilir. Yerleştirilen K-telleri dorsal ve volar kortekse ulaşıp redüksiyonu sağlar.

\section{Açık redüksiyon ve plak osteosentezi}

Plak osteosentezi ile çocuk önkol kırık tespiti, iskelet sistemi gelişimini tamamlamış veya tamamlamaya yakın olan çocuklarda kullanılmalıdır. Anatomik redüksiyon ve rijid tespit sağlar, aynı zamanda radyal eğimi ve malrotasyonu da tam olarak düzeltir. Daha büyük insizyon, turnike zamanının uzun oluşu ve diğer yöntemlere göre pahalı oluşu, dezavantajlar olarak belirtilmektedir.

\section{MONTEGGIA KIRIKLI ÇIKIĞI}

Illk kez 1814 yllında Giovanni Monteggia tarafından tanımlanmıştır. ${ }^{[20]}$ Açık tanımı; radius başı dislokasyonuna eşlik eden aynı taraf ulna kırığıdır. Benzer kırıklar görüldükçe Monteggia varyant şeklinde tanımlanmaktadır.

Çocuk önkol kırıklarının \%1'ini oluşturur. ${ }^{[21]}$ Kırık mekanizması; önkol hiperekstansiyonda veya hiperpronasyonda iken üzerine düşmektir. En sık görülen şekli; radius başının öne çıkığı ve ulna proksimal $1 / 3$ kırığıdır. Erkek çocuklarda kızlara göre üç kat fazla ve 4-10 yaş arası görülür.

Fizik muayenede travma mutlaka sorgulanmalıdır. Ayırıcı tanıda, travmatik olmadan radius başı çıkığına neden olan patolojiler akılda tutulmalıdır. Bunlar; tırnak-patella sendromu, Klinefelter sendromu, EhlersDanlos ve Klippel-Feil sendromları veya izole çıkıklar olarak bilinmektedir. Bu olgularda çıkık genellikle bilateraldir. Dolayısıyla tanıda diğer dirseğin de grafisinin alınması şarttır.

\section{Sinıflama}

Monteggia kırıklı çıkığı Bado sınıflamasına göre alt gruplara ayrilır (Şekil 11) ${ }^{[22]}$ :

Tip I: Öne açılanmış $1 / 3$ proksimal ulna kırığı ve radius başının öne çıkığı.

Tip II: Arkaya açılanmış 1/3 proksimal ulna ve/veya diyafiz kırığı ve radius başının arkaya çıkığı.

Tip III: Ulna metafizinin kırığı ve radius başının laterale veya anterolaterale çıkığı.

Tip IV: Ulna ve radiusun proksimal $1 / 3$ aynı seviyeden kırığı ve radius başı öne çıkığı.

\section{Tedavi}

Tedavisi, anestezi altında radyokapitellar eklemin redüksiyonu ve dirseğin $100^{\circ}$ derece ve üzerinde stabil olduğu noktada uzun kol alçı ile tespitidir. Bazı olgularda annüler bağın interpozisyonuna bağlı redüksiyon sağlanamaz ve açık redüksiyona geçilmesi gerekebilir. Açık redüksiyonda annüler bağ tamirinin de yapılması önerilir. Alçı sonrası birer haftalık takiplerle redüksiyon kaybı ihtimali izlenir ve altı hafta sonunda alçı çıkarılır. Geç kalınmış Monteggia kırıklı çıkığı tedavisinde ise önerilen ulnanın açık wedge osteotomisi ile kısaltılması ve radius başının redüksiyonudur. Gerekli durumlarda annüler bağ tamiri de yapılması önerilir. ${ }^{[4,21]}$ 


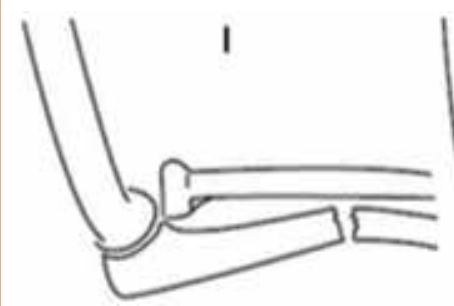

III
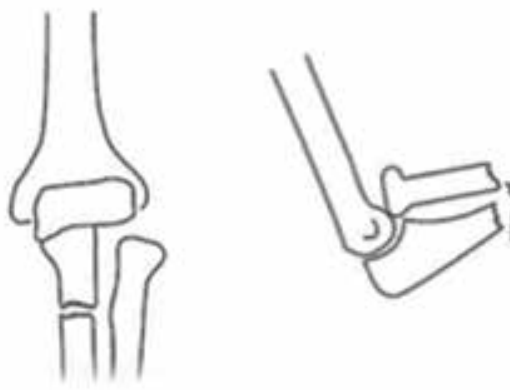

Şekil 11. Monteggia kırıklı çıkığında Bado sınıflaması.

\section{ÇOCUK ÖNKOL KIRIKLARI KONSERVATIF VE CERRAHI TEDAVI SONRASI SIK GÖRÜLEN KOMPLIKASYONLAR}

\section{1) Sinostoz}

Çocuklarda önkol kırıkları sonrasında nadir görülen ciddi bir komplikasyondur. Her iki kemikte de oluşan kallus, supinasyon ve pronasyonu tam kısıtlar. Yüksek enerjili travma, her iki kırığın da aynı seviyede olması, periosteal interpozisyon, cerrahi girişim, gecikmiş cerrahi girişim, başlangıç deplasmanının yüksek olması, tekrarlayan manipülasyonlar, radius başı eksizyonu, kafa travması gibi nedenler sinostoz riskini arttırır.

Üç tipi vardır (Şekil 12). Tip 2 yüksek enerjili travma ile görülürken, Tip 3 hafif travmalar sonrası da görülebilir.

Sinostozun tedavisi, iki kemik arasındaki ektopik dokunun eksizyonudur. Travma ile eksizyon arasında en az bir yıl beklenmelidir. Cerrahi tedavi için iskelet gelişiminin tamamlanmasını beklemek fonksiyonel kayıplara yol açmaktadır.

\section{2) Kompartman Sendromu}

En sık, kırık uçlarının fazla yer değiştirdiği, yüksek enerjili travmalardan sonra izlenir. Redüksiyon sonrası ağrısı devam eden ve ağrıdan dolayı pasif parmak hareketleri değerlendirilemeyen çocuklarda alçı atel haline getirilmeli ve olgular kompartman sendromu yönünden yakından izlenmelidir.

\section{3) Sinir Yaralanması}

Median, ulnar, posterior interosseöz sinir yaralanmaları görülebilir. Bunlar çoğunlukla geri dönüşümlüdür. Redüksiyon sonrasında, redüksiyon öncesi olmayan bir nörolojik defisit gelişmesi halinde, kırık parçaları arasında sinir sıkışmasından şüphelenilir ve sekiz hafta sonra eksplorasyon önerilir. ${ }^{[23]}$

\section{4) Diğer Komplikasyonlar}

Kırığın tekrarlaması, kötü kaynama, kırık hattında redüksiyonu engelleyen kas ve yumuşak doku interpozisyonu, enfeksiyon ve tespit materyalinin yetmezliğine bağlı oluşan sorunlar olarak sıralanabilir.

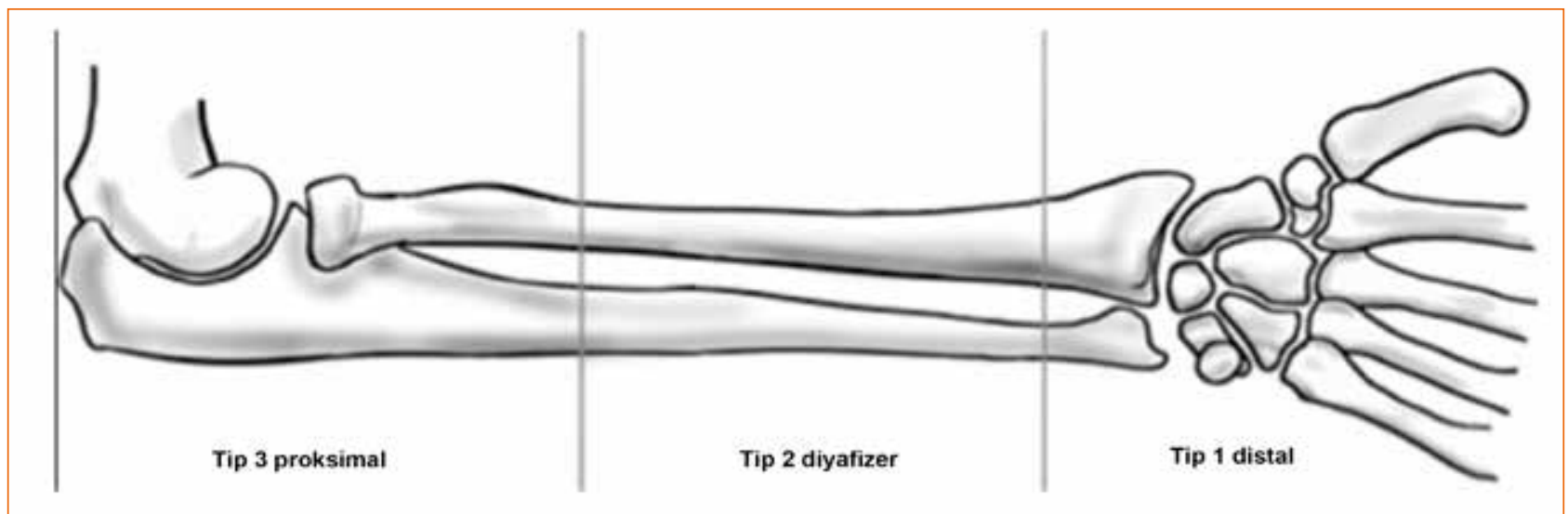

Şekil 12. Sinostoz tipleri. 


\section{SONUÇ}

Çocuklarda büyüme devam ettiği için, çocuk kırıkları ayrı bir öneme sahiptir ve fonksiyonel/anatomik sorunlar yaşanmaması için mükemmel bir şekilde tedavi edilmelidir. Çocuk önkol kırıklarında ilk tercih edilmesi gereken tedavi yöntemi uygun şartlarda ve titiz bir şekilde yapılan kapalı redüksiyon ve önkolu nötralde tutan dirsek üstü uzun kol alçı uygulamasıdır. Mümkünse hasta ilk 24 saat boyunca hastanede gözlem altında takip edilmelidir. Çocukların ve ailelerin ilk 24 saatte oluşabilecek komplikasyonlar konusunda uyarılmaları çok önemlidir. İlk üç hafta redüksiyon kaybının en sık gözlendiği dönem olduğu için, haftalık takip yapılmalıdır. Altı-sekiz hafta sonunda radyolojik kontrol yapılarak alçı çıkarılmalı ve rehabilitasyona başlanılmalıdır. Çocukların aktivite düzeyi yüksek olduğu için, kaynama gözlenmeden alçı çıkarılmamalıdır. Cerrahi tedavi gerekiyorsa, ilk 24 saat içinde yapılmalıdır. Minimal invaziv oluşu ve hastane yatış süresinin kısa olması nedeniyle, esnek intramedüller çivileme tercih edilmelidir.

\section{KAYNAKLAR}

1. Teoh KH, Chee YH, Shortt N, Wilkinson G, Porter DE. An ageand sex-matched comparative study on both-bone diaphyseal paediatric forearm fracture. J Child Orthop 2009;3(5):36773. Crossref

2. Lu D, Lin Z, Zhang JD, Chen H, Sun LJ. Treatment of pediatric forearm midshaft fractures: Is there a difference between types of orthopedic surgeon? Orthop Traumatol Surg Res 2017;103(1):119-22. Crossref

3. Kelly BA, Shore BJ, Bae DS, Hedequist DJ, Glotzbecker MP. Pediatric forearm fractures with in situ intramedullary implants. J Child Orthop 2016;10(4):321-7. Crossref

4. Mokawem M, Scott B. Children's forearm fractures. J Orthop Trauma 2015;29(1):57-68. Crossref

5. Armstrong PF, Joughin VE, Clarke HM. Pediatric Fractures of the Forearm, Wrist, and Hand. In: Green NE, Swiontkowski MF, editors. Skeletal Trauma in Children, 2nd ed. Philadelphia: WB Saunders; 1998. pp.161-70.

6. Pace JL. Pediatric and Adolescent Forearm Fractures: Current Controversies and Treatment Recommendations. J Am Acad Orthop Surg 2016;24(11):780-8. Crossref

7. Franklin CC, Robinson J, Noonan K, Flynn JM. Evidencebased medicine: management of pediatric forearm fractures. J Pediatr Orthop 2012;32 Suppl 2:S131-4. Crossref

8. Bryson DJ, Price KR. Upper limb fractures in children. Surgery (Oxford) 2017;35(1):18-26. Crossref
9. Antabak A, Luetic T, Ivo S, Karlo R, Cavar S, Bogovic M, Medacic SS. Treatment outcomes of both-bone diaphyseal paediatric forearm fractures. Injury 2013;44 Suppl 3:S11-5. Crossref

10. Vopat ML, Kane PM, Christino MA, Truntzer J, McClure P, Katarincic J, Vopat BG. Treatment of diaphyseal forearm fractures in children. Orthop Rev (Pavia) 2014;6(2):5325. Crossref

11. Franklin CC, Wren T, Ferkel E, Arkader A. Predictors of conversion from conservative to operative treatment of pediatric forearm fractures. J Pediatr Orthop B 2014;23(2):150-4. Crossref

12. Ho CA, Jarvis DL, Phelps JR, Wilson PL. Delayed union in internal fixation of pediatric both-bone forearm fractures. J Pediatr Orthop B 2013;22(4):383-7. Crossref

13. Du SH, Feng YZ, Huang YX, Guo XS, Xia DD. Comparison of pediatric forearm fracture fixation between single- and double-elastic stable intramedullary nailing. Am J Ther 2016;23(3):e730-6. Crossref

14. Di Gennaro GL, Stilli S, Trisolino G. Post-traumatic forearm nonunion in healthy skeletally immature children: A report on 15 cases. Injury 2017;48(3):724-30. Crossref

15. Şahin N, Akalın Y, Türker O, Özkaya G. ESIN and K-wire fixation have similar results in pediatric both-bone diaphyseal forearm fractures. Ulus Travma Acil Cerrahi Derg 2017;23(5):415-20. Crossref

16. Han B, Wang Z, Li Y, Xu Y, Cai H. Risk factors for refracture of the forearm in children treated with elastic stable intramedullary nailing. Int Orthop 2018. Crossref

17. Yong B, Yuan Z, Li J, Li Y, Southern EP, Canavese F, Xu H. Single Bone Fixation versus Both Bone Fixation for Pediatric Unstable Forearm Fractures: A Systematic Review and Metaanalysis. Indian J Orthop 2018;52(5):529-35. Crossref

18. Kruppa C, Bunge $P$, Schildhauer TA, Dudda M. Low complication rate of elastic stable intramedullary nailing (ESIN) of pediatric forearm fractures: A retrospective study of 202 cases. Medicine (Baltimore) 2017;96(16):e6669. Crossref

19. Monteggia GB. Instituzioni Chirurgiche. Milan: Presso Giuseppe Maspero, 1814. http://books.google.com/books? id=vzcHSIcYBhAC\&amp;oe=UTF-8

20. Reidy M, Faulkner A, Campell DM. Monteggia injuries and radial neck fractures in children. Orthop Trauma 2018;32(5):367-71. Crossref

21. Bado JL. La Lesion de Monteggia. Inter-Medica Sarandi; 1958. p.328.

22. Federer AE, Murphy JS, Calandruccio JH, Devito DP, Kozin SH, Slappey GS, Lourie GM. Ulnar Nerve Injury in Pediatric Midshaft Forearm Fractures: A Case Series. Orthop Trauma 2018;32(9):e359-65. Crossref

23. Koç F, Halıcıoğlu $O$, Akşit $S$. Which Findings May Suggest Physical Abuse? J Pediatr Res 2014;1(1):1-5. Crossref 